\title{
Reviewing the Diagnostic Classifications used for Low Back Pain in Physiotherapy-related Research.
}

Steve Milanese

University of South Australia, steve.milanese@unisa.edu.au

David Worth

University of South Australia, drworth@bigpond.net.au

Follow this and additional works at: https://nsuworks.nova.edu/ijahsp

Part of the Physical Therapy Commons, and the Physiotherapy Commons

This Manuscript has supplementary content. View the full record on NSUWorks here: https://nsuworks.nova.edu/ijahsp/vol17/iss4/8

\section{Recommended Citation}

Milanese S, Worth D. Reviewing the Diagnostic Classifications used for Low Back Pain in Physiotherapyrelated Research.. The Internet Journal of Allied Health Sciences and Practice. 2019 Jan 01;17(4), Article 8.

This Manuscript is brought to you for free and open access by the College of Health Care Sciences at NSUWorks. It has been accepted for inclusion in Internet Journal of Allied Health Sciences and Practice by an authorized editor of NSUWorks. For more information, please contact nsuworks@nova.edu. 


\title{
Reviewing the Diagnostic Classifications used for Low Back Pain in Physiotherapy-related Research.
}

\begin{abstract}
Background: The evidence-to-practice gap, where clinical practice does not reflect the findings from research evidence, has been identified as a concern in allied health disciplines such as physiotherapy. Failure to provide care according to current (research) evidence raises the potential that patients are receiving care that is either not needed, is ineffective, less effective than current research indicates, or potentially harmful. For research evidence to be translatable to clinical practice, the research should be seen to be applicable, i.e. the clinician should be able to recognise that the research study sample reflects their patient population. Method: This study presents a pragmatic clinical review of patient sampling from high level primary research trials investigating physical therapy for low back pain. Only studies where full text copies were freely accessible to clinicians were reviewed. The review collated the characteristics of the study subjects and explored how they related to standard clinical practice. Results: A total of 63 full text randomised controlled trials papers were identified and reviewed. Across the studies reviewed, the clinical presentations of included subjects were variably described, with inconsistencies in the diagnostic labels used, the characteristics of the symptoms reported and the nature of the exclusion criteria applied. Of concern was the lack of reporting of patient's clinical presentation according to standard clinical assessment findings to allow the clinician to gauge the applicability of the study. Conclusion: A core principle of clinical physiotherapy practice is the clinical assessment of the patient to identify the patient's specific presentation to individualise rehabilitation and exclude serious pathology. To close the evidencepractice gap, we either need to revisit standard clinical practice or focus on the reporting of the research evidence to ensure its applicability.
\end{abstract}

\section{Author Bio(s)}

Steve Milanese B.App.Sc.,Grad.Cert (Sports Physio) Grad.Dip (Ergonomics), M.App.Sc. (Manipulative Physiotherapy), PhD APAM, MCSP is an Associate Professor at the School of Health Sciences, University of South Australia and Director of the International Centre of Allied Health Evidence.

David Worth, PhD is a consultant Musculoskeletal Physiotherapist and an Adjunct Research Fellow at the International Centre of Allied Health Evidence, University of South Australia

\section{Acknowledgements}

N/A 


\title{
TIAHSP
}

\section{The Internet Journal of Allied Health Sciences and Practice}

Dedicated to allied health professional practice and education

Vol. 17 No. 4 ISSN 1540-580X

\section{Reviewing the Diagnostic Classifications used for Low Back Pain in Physiotherapy-Related Research}

\author{
Steve Milanese \\ David Worth \\ University of South Australia
}

Australia

\begin{abstract}
Background: The evidence-to-practice gap, where clinical practice does not reflect the findings from research evidence, has been identified as a concern in allied health disciplines such as physiotherapy. Failure to provide care according to current (research) evidence raises the potential that patients are receiving care that is either not needed, is ineffective, less effective than current research indicates, or potentially harmful. For research evidence to be translatable to clinical practice, the research should be seen to be applicable, i.e. the clinician should be able to recognise that the research study sample reflects their patient population. Method: This study presents a pragmatic clinical review of patient sampling from high level primary research trials investigating physical therapy for low back pain. Only studies where full text copies were freely accessible to clinicians were reviewed. The review collated the characteristics of the study subjects and explored how they related to standard clinical practice. Results: A total of 62 full text randomised controlled trials papers were identified and reviewed. Across the studies reviewed, the clinical presentations of included subjects were variably described, with inconsistencies in the diagnostic labels used, the characteristics of the symptoms reported and the nature of the exclusion criteria applied. Of concern was the lack of reporting of patient's clinical presentation according to standard clinical assessment findings to allow the clinician to gauge the applicability of the study. Conclusion: A core principle of clinical physiotherapy practice is the clinical assessment of the patient to identify the patient's specific presentation to individualise rehabilitation and exclude serious pathology. To close the evidence-practice gap, we either need to revisit standard clinical practice or focus on the reporting of the research evidence to ensure its applicability.
\end{abstract}

Keywords: low back pain, diagnosis, evidence-based practice gap 


\section{INTRODUCTION}

Evidence based practice (EBP) has become the dominant paradigm for a range of allied health professions, including physiotherapy. Benefits purported to follow the implementation of EBP into clinical practice relate to the grounding of clinical practice in scientific and empirical proof and achieving safer, more consistent, and more cost effective health care. ${ }^{1}$ This perceived quest for "objectivity" is underpinned by the process of EBP. By thoroughly searching the scientific literature and critically appraising the published scientific literature, we aim to rigorously, conscientiously and explicitly utilize the research evidence to inform our clinical practice.

Whilst the traditional model of EBP is based on the pillars of research evidence, patient preference, clinical experience, and practice context, there is a growing awareness of the importance of EBP implementation, which focuses on the translation of research evidence into clinical practice. The process of evidence implementation aims to close evidence - practice gaps, where the clinical practice does not reflect the findings from the research evidence. Most studies into the evidence-practice gap have focused on medicine and nursing, and identified that in countries such as the United States and Netherlands, at least $30 \%-40 \%$ of patients do not receive care according to current scientific (research) evidence. Of particular concern is the finding that $20 \%$ or more of the care provided is either not needed or potentially harmful to patients. ${ }^{2}$

Though evidence-practice gaps in physiotherapy are unlikely to result in significant harm to patients, they may lead to treatments with reduced efficacy. Barton et al reported an evidence-practice gap in the management of patello-femoral pain, with more therapists supporting use of a non-research evidence based intervention (kinesio-tape) compared to a research evidenced based treatment (prefabricated foot orthoses). ${ }^{3}$

Kitson et al presented a conceptual model for evidence implementation which consisted of a number of elements, including the nature of the evidence, the context in which the changes were to happen, and how the change was to be facilitated. ${ }^{4}$ The authors suggested that by giving equal recognition to each of the model's elements, practitioners should be able to implement research findings successfully into their clinical practice. When considering practices to facilitate research evidence implementation into clinical practice, it may be prudent to revisit the nature of the research evidence presented. A number of issues have been identified about the research evidence, including study methodologies that do not reflect clinical practice; inappropriate patient sampling and outcomes to gauge treatment success, and insufficient "physiotherapeutic" knowledge among researchers so that rigid protocols which ignore individual therapeutic "dose-response" relationships are used.

According to the traditional EBP model in the area of intervention-based research, randomised controlled trials (RCTs) are considered the highest level of primary research design as a result of the inherent strength of this research design. Whilst there have been some discussion about the relevance of this research design to complex allied health interventions such as physiotherapy within the area of EBP, RCTs remain the highest primary level of research evidence. ${ }^{5}$

One aspect of the RCT methodology which strengthens this specific design relates to the appropriate sampling of subjects for inclusion into the study. The sampling of subjects within an RCT requires a balance between the need for scientific rigor, by controlling for potential confounders through strict inclusion and exclusion criteria, and the need to reflect the characteristics of the population for which the study purports to be applicable to. For a clinician, the ability to implement RCT research evidence into clinical practice will depend on the clinician identifying that the research studies' subjects reflect the clinician's patients. The less that the subjects recruited into the study can be linked to the patients that the clinician sees, the less likely the clinician will uptake the research findings.

In clinical practice, physiotherapy clinicians undertake clinical assessments to identify the key attributes of their patients. The World Confederation of Physical Therapists (WCPT) recommends that physiotherapists should undertake a comprehensive assessment of the patient, evaluate these findings to make clinical judgments, and undertake an appropriate intervention. They recommend that through a process of clinical reasoning that identifies existing or potential impairments, activity limitations, participation restrictions, environmental influences or abilities/disabilities, a diagnosis is made. The purpose of this diagnosis ".....is to guide physical therapists in determining the prognosis and most appropriate intervention/treatment strategies for patients/clients and in sharing information with them." 6

In the management of low back pain, a standard part of physiotherapy practice is that an assessment, including both a subjective and objective examination, is carried out to identify the patient's specific presentation. It is a fundamental approach to physiotherapy, as the profession has moved away from the role of a technician, that the treatment approach should be individualized to the patient's presentation and not be recipe-based. ${ }^{7}$ Whilst some authors have queried the evidence associated with this approach, the authors also acknowledge that the studies were often flawed, with small subject numbers and significant

( The Internet Journal of Allied Health Sciences and Practice, 2019 
biases. ${ }^{8}$ In essence, we still do not know, apart from therapist's clinical experience and patient preference, whether individualized treatment works.

Whilst the diagnostic capacity of clinical examination tests used by physiotherapists is often poor, the information gained can be used to individualize the patients treatment independent of the diagnostic label applied. For example, the treatment for patients with low back pain aggravated by flexion activities is different than that for patients with low back pain during extension type activities, independent on what diagnostic label we might apply to the patients.

Importantly, the clinical assessment seeks not only to differentiate patients according to their clinical presentation, but also to identify those with serious spinal pathology, as they may present with flags that may be identified in the clinical assessment.

\section{Study Aims}

This study critically reviewed recent RCT research evidence in terms of the subjects sampled and how it reflected the patients that may be seen in clinical practice. The study had two main aims:

a) To identify how study samples were characterized in RCTs on the use of physical therapy for low back pain in adults

b) To identify how the samples were characterized against standard physiotherapy assessment processes.

The aim of this study was not to critically appraise the internal validity or quality of the studies or to review the study findings, but to explore how likely a clinician could take the studies' findings into clinical practice; that is, the applicability/external validity of the research evidence.

\section{METHODS}

A pragmatic search of the published evidence related to the physiotherapeutic management of low back pain in adults was undertaken in October 2017. The aim of this search was not to undertake an academic systematic review but to perform a search that a clinician may undertake in clinical practice to identify the most recent highest levels of primary research evidence to treat their patient with low back pain. The access to journals was limited to those that a clinician would be able to access in full text in a publically available database, without subscribing to a database/journal/library.

\section{Selection of Studies}

Participants

Studies were included if they involved adult patients who had low back pain.

\section{Intervention}

Studies were included if the intervention was based on any physiotherapy/physical therapy treatment of any form.

\section{Outcomes}

Outcomes were not the focus of this review and therefore all outcomes were included.

Eligible studies were identified using a search strategy of key terms: "low back pain," "physiotherapy," "physical therapy." and "randomised controlled trial" in a publically available database (PubmedC) from January 2015 to September 2017. A two-year window of publication was chosen to ensure only the most recent evidence was reviewed. Inclusion criteria were established with all studies involving adults with low back pain and investigating the use of any physiotherapy/ physical therapy modality. All titles and abstracts were independently screened for inclusion by the two authors, and any disagreements were resolved by consensus. Where there was uncertainty, the full text of the article was retrieved and screened.

\section{Data Extraction}

\section{Study characteristics}

For all included studies, both authors independently extracted data on the inclusion criteria reported by the authors for inclusion of subjects into the study. A specifically designed data extraction tool was used to collate the data used for this review. Specific data extracted from the studies included author, year, inclusion criteria, exclusion criteria, diagnostic label (if relevant), assessment findings (if relevant), pain description (area, severity, duration), intervention 


\section{RESULTS}

A total of 62 RCT studies, available freely in full text, and published between January 2015 and December 2017 were located (see Figure 1). ${ }^{9-70}$ There were no disagreements between the two authors from screening title and abstract

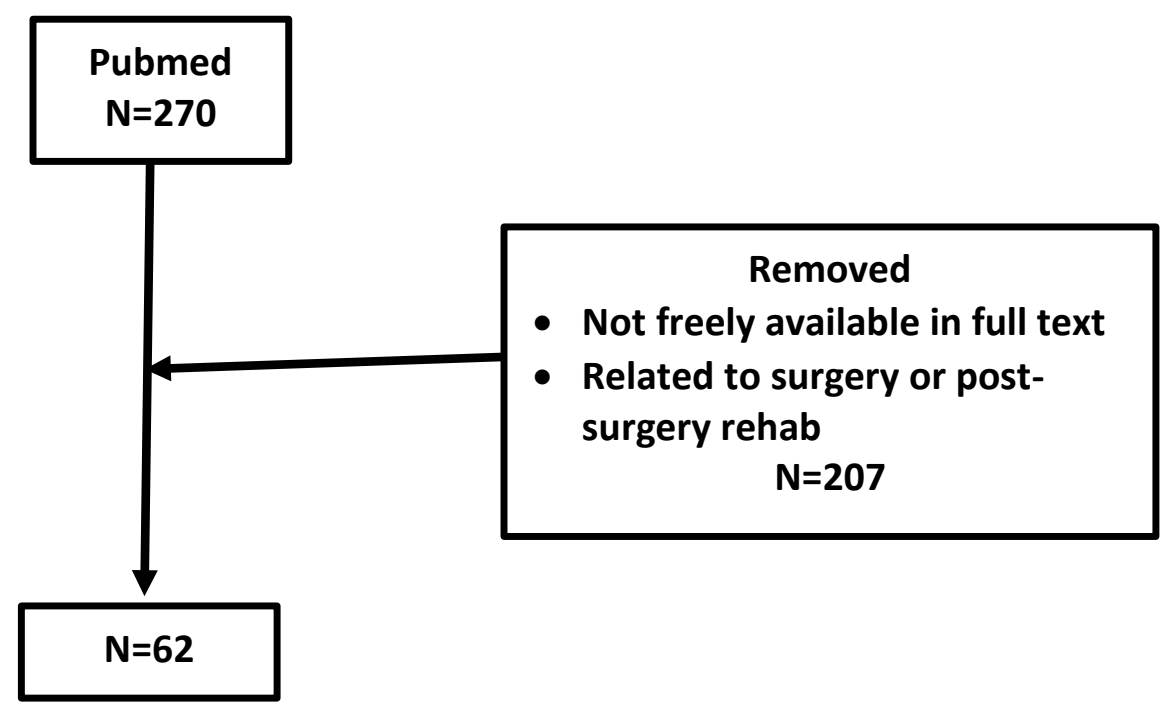

Figure 1: Consort diagram of review process

Very few studies identified the patho-anatomical lesion that was potentially involved, with only one study labelling the patients' patho-anatomical cause for their low back pain. ${ }^{25}$ The most common diagnostic labels used were "chronic low back pain" ( $n=19$ $(30.1 \%)$ and "non-specific chronic low back pain" ( $n=14(22.2 \%)$. The range of diagnostic labels are presented in Table1.

When labelling the patients clinical presentation, the pain was most commonly characterized by area of symptoms (i.e., low back), temporal aspects (acute, subacute, and chronic), causes (non-specific low back pain, lumbar disc herniation with associated radiculopathy) or behavior (mechanical, persistent, and recurrent). The definitions for these are presented in Table 2.

Table 1. Diagnostic labels reported in the study

\begin{tabular}{|c|l|c|}
\hline & Diagnostic label & Number of studies \\
\hline 1 & Chronic LBP & 21 \\
\hline 2 & Non-specific chronic LBP & 18 \\
\hline 3 & Low Back pain & 13 \\
\hline 5 & Non-specific LBP & 8 \\
\hline 5 & Sub-acute LBP & 5 \\
\hline 7 & Acute/recent onset LBP & 3 \\
\hline 8 & Mechanical BLBP & 2 \\
\hline 9 & Nonspecific persistent LBP & 2 \\
\hline 10 & Persistent non-specific LBP & 2 \\
\hline 11 & Chronic mechanical LBP & 2 \\
\hline 12 & Chronic or recurrent LBP with reduced hip rotation & 1 \\
\hline 13 & Mechanical Chronic LBP & 1 \\
\hline 14 & LBP and movement control impairment & 1 \\
\hline 15 & Nonspecific chronic mechanical LBP & 1 \\
\hline 16 & Non-specific chronic, recurrent LBP & 1 \\
\hline 17 & Lumbar disc herniation with associated radiculopathy & 1 \\
\hline 18 & Persistent Low Back Pain & 1 \\
\hline
\end{tabular}

*Total number of studies $>62$ as some studies report more than one diagnostic label 
Table 2: Definitions for characterizing subject's pain

\begin{tabular}{|c|c|}
\hline Characterization & Definition \\
\hline Acute & $\bullet<4$ weeks 25 \\
\hline Subacute & $\begin{array}{l}\text { - } 4 \text { to } 12 \text { weeks } 25 \\
\text { - }>4 \text { weeks } 69 \\
\text { - } 3 \text { to } 12 \text { weeks } 28\end{array}$ \\
\hline Chronic & $\begin{array}{l}->6 \text { weeks } 54 \\
\bullet>12 \text { weeks/3 months } 19,25,28,29,31,42,65,70 \\
\bullet>6 \text { months } 39,63 \\
\bullet>12 \text { months } 64\end{array}$ \\
\hline Persistent/Recurrence & $\begin{array}{l}\text { - from "very often" to "always" } 15 \\
\text { - }>3 \text { episodes a year } 42 \\
\text { - Symptoms on less than half the days in a } 12 \text { month period in multiple episodes } 68 \\
-\geq 1 \text { episode(s) of LBP over the previous three years, }{ }^{16}\end{array}$ \\
\hline Mechanical Low Back pain & - LBP of a nociceptive mechanical character from assessment ${ }^{37}$ \\
\hline
\end{tabular}

A number of studies also used measures of severity and disability to further classify their study subject's clinical presentation. Table 3 presents the definitions used for severity and disability characteristics.

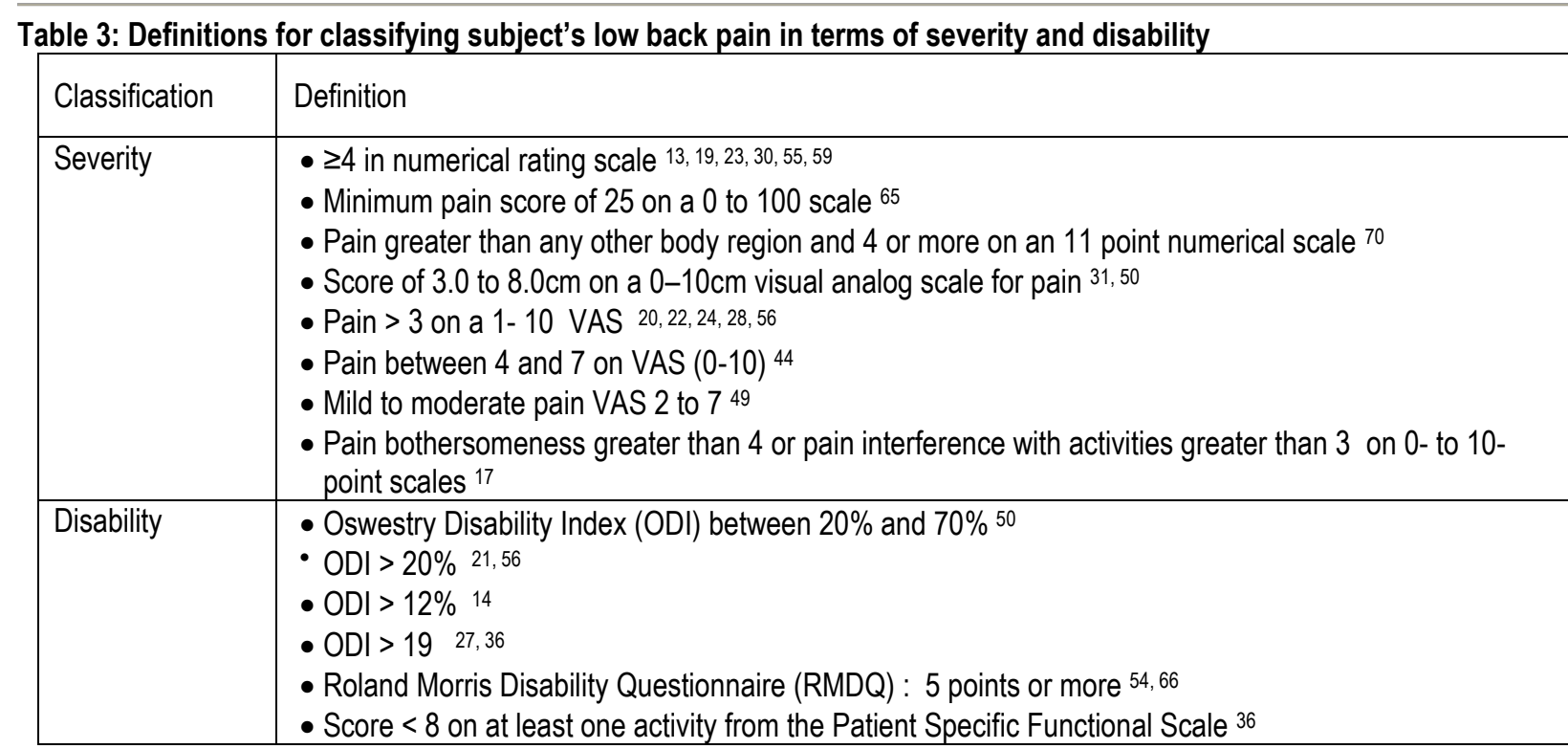

When describing the process for including patients with low back pain into the study fifteen studies $(23.8 \%)$ of reported the clinical assessments that were undertaken (see Table 4). 
Table 4: Clinical assessments performed as part of the sampling process

\begin{tabular}{|c|c|}
\hline Clinical Assessment & Study \\
\hline Lumbar range of movement & $\begin{array}{l}\text { Ammar et al|12, Gyulai et a }\left.\right|^{24} \text {, Hidalgo et al26, Murtezani et al }{ }^{13} \text {, Natour et al }{ }^{44} \text {, Shah \& Kage }{ }^{57} \text {, } \\
\text { Vavrek et al65, Waqqar et al67 }\end{array}$ \\
\hline Neurological testing & Ammar et al|12, Fritz et al|21 Garcia et al22, Hahne et al|25, Vavrek et al65, \\
\hline Posture Assessment & Ammar et al ${ }^{12}$, Patti et al ${ }^{48}$ \\
\hline Strength & Ammar et al ${ }^{12}$, Steele et al60 \\
\hline Balance & Patti et al ${ }^{48}$ \\
\hline Gait analysis & Steele et $a^{160}$ \\
\hline Motor control & Lehtola et a|33, Saner et a|54 \\
\hline
\end{tabular}

\section{DISCUSSION}

There has been discussion in the literature about the evidence-practice gap and the need for clinicians to keep up to date with the evidence associated with their patient's clinical management. Issues have been raised about the difficulties associated with the uptake of evidence, particularly related to the amount of literature that is published each year and the ability of a clinician to access and utilize this rising tide of evidence.

This review took a clinically pragmatic view of the evidence translation by only sourcing evidence that would be available to a practicing clinician without having to pay for journal subscriptions or have access to academic library databases. This is also the case in many universities in developing countries who are unable to subscribe to expensive or extensive journal sets. We felt that this was important, as published systematic reviews often fail to identify the key sampling criteria in the included RCTs, making it difficult for the clinician to gauge the study sample applicability. In these case, the clinician would need to go back to the primary source, the published RCT.

Despite these limitations, we found 62 full text papers from 270 papers reporting on RCTs for the physiotherapeutic management of a patient with low back pain over the period from January 2015 to October 2017. This is a significant body of literature and would represent a major time commitment for the clinician to access, read, and appraise. We acknowledge that this number of studies is the worst case scenario as the clinician would usually limit their search by intervention type, but reflects one of the current challenges to EBP implementation - the wealth of published evidence.

This number of studies also explains the growing popularity of secondary evidence sources such as systematic reviews and clinical guidelines; however, we chose not to include these secondary evidence sources. The RCT studies represent the primary source for the study and allowed us to explore the characteristics of the study subjects that would be used by a clinician to determine if they could apply this information when considering how to implement the research evidence into their clinical practice. As described, systematic reviews often do not report the specific criteria of the subjects sampled for a RCT.

When reading a study, the first information that the clinician can use to help determine the applicability of the study to their patient cohort is the diagnostic label used. This study found a wide range of diagnostic labels applied to patients with low back pain. These labels differentiated the LBP based on temporality (acute, vs, subacute, vs chronic), causes (non-specific, lumbar disc herniation with associated radiculopathy) or behavior (mechanical), with varying consistency on the definitions used for these across the studies. Acute was defined as less than 3 to 4 weeks and sub-acute as between 3 to 4 weeks and 12 weeks. Chronic LBP was defined as greater than 6 weeks, $>12$ weeks, $>6$ months, and $>12$ months. 19,23,28,29,31,39,42,54,63-65,70

When subjects were recruited based on measures of disability and severity, inconsistences were also reported in the definitions used. Severity was most commonly based on the VAS 1- 10 scale; however, the cut-off point for inclusion in the study ranged from 2 to 4 out of 10. Measures of disability used included the Oswestry Disability Index (ODI), the Roland Morris Disability Questionnaire (RMDQ) and the Patient Specific Functional Scale. There was also a lack of consistency in the cut-off with ODI scores ranging from $12 \%$ to $20 \%$.

Chronic low back pain and non-specific low back pain were the most predominant diagnostic labels, being part of the diagnostic labels used by $71 \%$ of studies. The diagnostic label "non-specific low back pain" implies that there is no known patho-anatomical cause for the low back pain. Patho-anatomical causes of low back pain include epidural abscess, compression fracture, 
spondyloarthropathy, malignancy, cauda equina syndrome, radiculopathy, or spinal canal stenosis, with all other causes of low back pain being considered non-specific low back pain. In this review, other patho-anatomical causes for low back pain that were reviewed included pregnancy, infection, inflammatory joint diseases, disc herniation, spondylolisthesis, and ankylosing spondylitis. Only one study in this review diagnosed the patients low back pain presentation with a patho-anatomical cause ${ }^{25}$

Some authors have suggested that as non-specific low back pain does not have a known patho-anatomical cause, there are, therefore, no specific treatments that can be provided. ${ }^{8}$ This of course presupposes that we understand all potential pathoanatomical structures and have the ability to diagnose them. Most studies in this review reported the absence of patho-anatomical causes for the low back pain; however, very few studies reported how they identified if there was a patho-anatomical cause for the subjects low back pain prior to inclusion into the trial. A number of the studies reported that the patients were cleared of these causes by their medical practitioner or through self-report, but without any evidence of the assessment/examination used, along with the corresponding sensitivity/specificity of the tests used, the diagnosis of non-specific low back pain appears optimistic.

The label "non-specific low back pain" suggests that the low back pain is non-specific. Without reports of clinical assessment findings, it is difficult to identify if the patient's presentation was specific or different from the others within the sample. It is therefore difficult to translate the findings from this research into clinical practice.

When auditing the research evidence against standard clinical practice, there was a consistent lack of use of standard clinical assessment and presentation of assessment findings to classify patients amongst the research studies. Whilst a number of studies reported using clinical assessment tests such as range of spinal movement and posture assessment, very few studies reported the findings and sub-classified subject responses to the intervention based on their clinical presentation. This process is often difficult in low back pain research where recruitment is problematic, leaving researchers with small subject samples. Any attempts to sub-classify patients according to their clinical presentations leaves the researcher with underpowered statistical analyses. Whilst this is an issue for the strength of findings associated with a single study, if studies utilized diagnostic classifications, based on standard clinical assessment and standardized outcomes, there is an opportunity for combining results of a number of studies using meta-analytical procedures. This may help overcome one of the major issues in clinical research in developed countries sourcing sufficient patient numbers to allow sub-classifications of patient presentations.

A major issue in contemporary health care is how best to close the perceived gaps between evidence and practice that continue to persist in the management of low back pain. The general approach has been to look at what the clinician is doing and try to understand why the clinician is not using the research evidence.

This review highlights that the research evidence that is currently available is not reflective of current clinical practice. For the evidence-practice gap to close, we either need to change clinical practice or change the way research evidence is collected and presented.

To change clinical practice to fit with the research evidence, the balance of the evidence suggests that for the management of low back pain, we should eliminate clinical assessment, apart from either a questionnaire to identify red flags and the patients understanding of significant pathology they may have, or a letter from their medical practitioner to clear them, and treat all low back pain patients the same, as most have non-specific low back pain. This approach would appear to be in conflict with the concept of clinical reasoning.

\section{CONCLUSION}

To change the way the research evidence is presented, we should see more sub-classification of patients based on their clinical assessment findings as standard secondary outcomes. Even just basing this classification on patient's relative movement restrictions will more reflect common clinical practice. Whilst this may lead to under-powered analyses of these secondary outcomes, the data presented can be combined across studies. The identification of low back pain presentation types will facilitate the development of management strategies that directly target the low back pain presentation and its consequent disability, and not a theoretical model of what could be wrong with a patient.

Until research evidence is able to be transferred into clinical practice and until researchers start to talk to clinicians, we will remain with an evidence- practice gap in the management of patients with low back pain.

( The Internet Journal of Allied Health Sciences and Practice, 2019 


\section{References}

1. Pope C. Resisting evidence: the study of evidence-based medicine as a contemporary social movement. Health. 2003; 7:3:267-282.

2. Grol R, \& Wensing M. What drives change? Barriers to and incentives for achieving evidence-based practice. Medical Journal of Australia. 2004; 180:6 Suppl: S57.

3. Barton $\mathrm{C}$, Crossley $\mathrm{K} \&$ Rathleff $\mathrm{M}$. There is an evidence-practice gap in patellofemoral pain management that can be bridged. Journal of Science and Medicine in Sport. 2017; 20: e20-e21.

4. Kitson A, Harvey G \& McCormack B. Enabling the implementation of evidence based practice: a conceptual framework. BMJ Quality \& Safety. 1998: 7:3: 149-158.

5. Milanese S. The use of RCT's in manual therapy-are we trying to fit a round peg into a square hole?. Manual Therapy. 2011; 16:4: 403-405.

6. World Confederation for Physical Therapy 2015. Policy statement: Description of physical therapy. https://www.wcpt.org/policy/ps-descriptionPT (Access date 10th February 2018)

7. Bishop MD, Torres-Cueco R, Gay CW, Lluch-Girbés E, Beneciuk JM \& Bialosky JE. What effect can manual therapy have on a patient's pain experience? Pain Management. 2015;5:6: 455-464.

8. Maher C, Underwood M \& Buchbinder R. Non-specific low back pain. The Lancet. 2017; 18: 389:736-47.

9. Aboagye E, Karlsson M, Hagberg J. \& Jensen I. Cost-effectiveness of early interventions for non-specific low back pain: a randomized controlled study investigating medical yoga, exercise therapy and self-care advice. Journal of Rehabilitation Medicine. 2015;47:2:167-173.

10. Added MAN, Costa LOP, de Freitas DG, Fukuda TY, Monteiro R, Salomão EC, de Medeiros FC \& Costa LDCM. Kinesio Taping does not provide additional benefits in patients with chronic low back pain who receive exercise and manual therapy: a randomized controlled trial. Journal of Orthopaedic \& Sports Physical Therapy. 2016; 46:7: 506-513.

11. Akhtar MW, Karimi H \& Gilani, SA. Effectiveness of core stabilization exercises and routine exercise therapy in management of pain in chronic non-specific low back pain: A randomized controlled clinical trial. Pakistan Journal of Medical Sciences. 2017; 33:4: 1002.

12. Ammar TARA. Monochromatic infrared photo energy versus low level laser therapy in chronic low back pain. Journal of Lasers in Medical Sciences. 2015; 6: 4: 157.

13. Bello Al, Quartey JNA \& Lartey M. Efficacy of behavioural graded activity compared with conventional exercise therapy in chronic nonspecific low back pain: Implication for direct health care cost. Ghana Medical Journal, 2015; 49:3:173-180.

14. Boucher JA, Preuss R, Henry SM, Dumas JP \& Larivière C. The effects of an 8-week stabilization exercise program on lumbar movement sense in patients with low back pain. BMC Musculoskeletal Disorders. 2016; 17:1: 23.

15. Castagnoli C, Cecchi F, Del Canto A, Paperini A, Boni R, Pasquini G, Vannetti F \& Macchi C. Effects in short and long term of Global Postural Reeducation (GPR) on chronic low back pain: a controlled study with one-year follow-up. The Scientific World Journal. 2015.

16. Chaléat-Valayer E, Denis A, Abelin-Genevois K, Zelmar A, Siani-Trebern F, Touzet S, Bergeret A, Colin C \& Fassier JB. Long-term effectiveness of an educational and physical intervention for preventing low-back pain recurrence: a randomized controlled trial. Scandinavian Journal of Work, Environment \& Health. 2016; 42:6: 510-519.

17. Cherkin DC, Sherman KJ, Balderson BH, Cook AJ, Anderson ML, Hawkes RJ, Hansen KE \& Turner JA. Effect of mindfulness-based stress reduction vs cognitive behavioral therapy or usual care on back pain and functional limitations in adults with chronic low back pain: a randomized clinical trial. JAMA. 2016;315:12:1240-1249.

18. Díaz-Arribas MJ, Kovacs FM, Royuela A, Fernández-Serrano M, Gutiérrez-Fernández L, San Martin-Pariente O, Abraira V, Ramos-Sánchez M, Llorca-Palomera R, Pardo-Hervás P \& Gestoso M. Effectiveness of the Godelieve Denys-Struyf (GDS) method in people with low back pain: cluster randomized controlled trial. Physical Therapy. 2015; 95:3: 319-336.

19. Ferrandiz MEA, Nijs J, Gidron Y, Roussel N, Vanderstraeten R, Van Dyck D, Huysmans E \& De Kooning, M. Auto-targete $\mathrm{d}$ neurostimulation is not superior to placebo in chronic low back pain: a fourfold blind randomized clinical trial. Pain Physician. 2016;19:5:E707-E719.

20. Ford JJ, Hahne AJ, Surkitt LD, Chan AY, Richards MC, Slater SL, Hinman RS, Pizzari T, Davidson M \& Taylor NF. Individualised physiotherapy as an adjunct to guideline-based advice for low back disorders in primary care: a randomised controlled trial. Br J Sports Med. 2016;50:4:237-245.

21. Fritz JM, Magel JS, McFadden M, Asche C, Thackeray A, Meier W \& Brennan G. Early physical therapy vs usual care in patients with recent-onset low back pain: a randomized clinical trial. JAMA. 2015; 314:14:1459-1467.

22. Garcia AN, Costa LDCM, Hancock M \& Costa LOP. Identifying patients with chronic low back pain who respond best to mechanical diagnosis and therapy: secondary analysis of a randomized controlled trial. Physical Therapy. 2016; 96:5:623630.

(C) The Internet Journal of Allied Health Sciences and Practice, 2019 
23. Goertz CM, Xia T, Long CR, Vining R, Pohlman KA, DeVocht JW, Gudavalli MR, Owens Jr EF, Meeker WC \& Wilder DG. Effects of spinal manipulation on sensorimotor function in low back pain patients-a randomised controlled trial. Manual Therapy. 2016;21:183-190.

24. Gyulai F, Rába K, Baranyai I, Berkes E \& Bender T. BEMER therapy combined with physiotherapy in patients with musculoskeletal diseases: a randomised, controlled double blind follow-up pilot study. Evidence-Based Complementary and Alternative Medicine. 2015.

25. Hahne AJ, Ford JJ, Hinman RS, Richards MC, Surkitt LD, Chan AY, Slater SL \& Taylor NF. Individualized functional restoration as an adjunct to advice for lumbar disc herniation with associated radiculopathy. A preplanned subgroup analysis of a randomized controlled trial. The Spine Journal. 2017; 17:3:346-359.

26. Hidalgo B, Pitance L, Hall T, Detrembleur C \& Nielens H. Short-term effects of Mulligan mobilization with movement on pain, disability, and kinematic spinal movements in patients with nonspecific low back pain: a randomized placebocontrolled trial. Journal of Manipulative \& Physiological Therapeutics. 2015; 38:6:365-374.

27. Jacobs JV, Lomond KV, Hitt JR, DeSarno MJ, Bunn JY \& Henry SM. Effects of low back pain and of stabilization or movement-system-impairment treatments on induced postural responses: A planned secondary analysis of a randomised controlled trial. Manual Therapy. 2016; 21:210-219.

28. Kent $P$, Laird $R$ \& Haines $T$. The effect of changing movement and posture using motion-sensor biofeedback, versus guidelines-based care, on the clinical outcomes of people with sub-acute or chronic low back pain-a multicentre, clusterrandomised, placebo-controlled, pilot trial. BMC Musculoskeletal Disorders.2015;16:1: 131.

29. Kliziene I, Sipaviciene S, Vilkiene J, Astrauskiene A, Cibulskas G, Klizas S \& Cizauskas G. Effects of a 16-week Pilates exercises training program for isometric trunk extension and flexion strength. Journal of Bodywork and Movement Therapies. 2017; 21:1: 124-132.

30. Kumar S, Rampp T, Kessler C, Jeitler M, Dobos GJ, Lüdtke R, Meier L \& Michalsen A. Effectiveness of Ayurvedic Massage (Sahacharadi Taila) in Patients with Chronic Low Back Pain: A Randomized Controlled Trial. The Journal of Alternative and Complementary Medicine. 2017;23:2:109-115.

31. Lawand P, Júnior IL, Jones A, Sardim C, Ribeiro LH \& Natour J. Effect of a muscle stretching program using the global postural reeducation method for patients with chronic low back pain: a randomized controlled trial. Joint Bone Spine. 2015; 82:4:272-277.

32. Lee JH, Park YH \& Jang SH. The effects of stabilization exercise with an oral assistive device on pain and functionality of low back pain patients. Journal of Physical Therapy Science. 2015;27:10:3031-3034.

33. Lehtola V, Luomajoki H, Leinonen V, Gibbons S \& Airaksinen O. Sub-classification based specific movement control exercises are superior to general exercise in sub-acute low back pain when both are combined with manual therapy: A randomized controlled trial. BMC Musculoskeletal Disorders. 2016;17:1: 135.

34. Licciardone JC, Gatchel RJ \& Aryal S. Recovery from chronic low back pain after osteopathic manipulative treatment: a randomized controlled trial. Journal of American Osteopath Association. 2016; 116:3:144-155.

35. Licciardone JC, Gatchel RJ \& Aryal S. Targeting patient subgroups with chronic low back pain for osteopathic manipulative treatment: responder analyses from a randomized controlled trial. Journal of American Osteopath Association, 2016; 116:3 : 156-68.

36. Lomond KV, Jacobs JV, Hitt JR, DeSarno MJ, Bunn JY, Henry SM. Effects of low back pain stabilization or movement system impairment treatments on voluntary postural adjustments: a randomized controlled trial. Spine Journal. 2015;15:4:596-606.

37. Michaelson P, Holmberg D, Aasa B \& Aasa U. High load lifting exercise and low load motor control exercises as interventions for patients with mechanical low back pain: a randomized controlled trial with 24-month follow-up. Journal of Rehabilitation Medicine. 2016; 48:5:456-463.

38. Miyamoto GC, Moura KF, Franco YRDS, de Oliveira NTB, Amaral DDV, Branco ANC, da Silva ML, Lin C \& Cabral CMN. Effectiveness and cost-effectiveness of different weekly frequencies of Pilates for chronic low back pain: randomized controlled trial. Physical Therapy. 2016; 96:3: 382-389.

39. Monticone M, Ambrosini E, Rocca B, Cazzaniga D, Liquori V \& Foti C. Group-based task-oriented exercises aimed at managing kinesiophobia improved disability in chronic low back pain. European Journal of Pain. 2016; 20:4 : 541-551.

40. Morris M, Pellow J, Solomon EM \& Tsele-Tebakang T. Physiotherapy and a homeopathic complex for chronic low-back pain due to osteoarthritis: a randomized, controlled pilot study. Alternative Therapies in Health and Medicine. 2016;22:1 : 48.

41. Mostagi FQRC, Dias JM, Pereira LM, Obara K, Mazuquin BF, Silva MF, Silva MAC, de Campos RR, Barreto MST, Nogueira JF \& Lima TB. Pilates versus general exercise effectiveness on pain and functionality in non-specific chronic low back pain subjects. Journal of Bodywork and Movement Therapies. 2015 ;19:4: 636-645.

42. Murray A, Hall AM, Williams GC, McDonough SM, Ntoumanis N, Taylor IM, Jackson B, Matthews J, Hurley DA \& Lonsdale C. Effect of a self-determination theory-based communication skills training program on physiotherapists' psychological

( The Internet Journal of Allied Health Sciences and Practice, 2019 
support for their patients With chronic low back pain: A randomized controlled trial. Archives of Physical Medicine and Rehabilitation. 2015;96:5:809-816.

43. Murtezani A, Govori V, Meka VS, Ibraimi Z, Rrecaj S \& Gashi S. A comparison of Mckenzie therapy with electrophysical agents for the treatment of work related low back pain: A randomized controlled trial. Journal of Back and Musculoskeletal Rehabilitation. 2015;28:2: 247-253.

44. Natour J, Cazotti LDA, Ribeiro LH, Baptista AS \& Jones A. Pilates improves pain, function and quality of life in patients with chronic low back pain: a randomized controlled trial. Clinical Rehabilitation.2015;29:1:59-68.

45. Norbye AD, Omdal AV, Nygaard ME, Romild U, Eldøen G \& Midgard R. Do Patients With Chronic Low Back Pain Benefit From Early Intervention Regarding Absence From Work?: A Randomized, Controlled, Single-Center Pilot Study. Spine. 2016; 41:21: E1257.

46. Oksuz S \& Unal $E$. The effect of the clinical pilates exercises on kinesiophobia and other symptoms related to osteoporosis: A randomised controlled trial. Complementary Therapies in Clinical Practice. 2017; 26:68-72.

47. Paanalahti K, Wertli M, Held U, Åkerstedt T, Holm LW, Nordin M \& Skillgate E. Spinal pain—good sleep matters: a secondary analysis of a randomized controlled trial. European Spine Journal. 2016; 25:3: 760-765.

48. Patti A, Bianco A, Paoli A, Messina G, Montalto MA, Bellafiore M, Battaglia G, lovane A \& Palma A. Pain perception and stabilometric parameters in people with chronic low back pain after a Pilates exercise program: a randomized controlled trial. Medicine. 2016; 95(2).

49. Paungmali A, Henry LJ, Sitilertpisan P, Pirunsan U \& Uthaikhup S. Improvements in tissue blood flow and lumbopelvic stability after lumbopelvic core stabilization training in patients with chronic non-specific low back pain. Journal of Physical Therapy Science. 2016; 28:2: 635-640.

50. Perry J, Green A, Singh S \& Watson P. A randomised, independent groups study investigating the sympathetic nervous system responses to two manual therapy treatments in patients with LBP. Manual Therapy. 2015;20:6: 861-867.

51. Petersen $T$, Christensen $R$ \& Juhl $C$. Predicting a clinically important outcome in patients with low back pain following McKenzie therapy or spinal manipulation: a stratified analysis in a randomized controlled trial. BMC Musculoskeletal Disorders. 2015; 16:1: 74.

52. Pincus T, Anwar S, McCracken LM, McGregor A, Graham L, Collinson M, McBeth J, Watson P, Morley S, Henderson J \& Farrin AJ. Delivering an Optimised Behavioural Intervention (OBI) to people with low back pain with high psychological risk; results and lessons learnt from a feasibility randomised controlled trial of Contextual Cognitive Behavioural Therapy (CCBT) vs. Physiotherapy. BMC Musculoskeletal Disorders. 2015; 16:1: 147.

53. Saner J, Kool J, Sieben JM, Luomajoki H, Bastiaenen CH \& de Bie RA. A tailored exercise program versus general exercise for a subgroup of patients with low back pain and movement control impairment: a randomised controlled trial with one-year follow-up. Manual Therapy. 2015;20:5: 672-679.

54. Saner J, Sieben JM, Kool J, Luomajoki H, Bastiaenen CH \& de Bie RA. A tailored exercise program versus general exercise for a subgroup of patients with low back pain and movement control impairment: Short-term results of a randomised controlled trial. Journal of Bodywork and Movement Therapies. 2016;20:1:189-202.

55. Saper RB, Lemaster C, Delitto A, Sherman KJ, Herman PM, Sadikova E, Stevans J, Keosaian JE, Cerrada CJ, Femia AL \& Roseen EJ. Yoga, physical therapy, or education for chronic low back pain: a randomized noninferiority trial. Annals of Internal Medicine.2017; 167:2:85-94.

56. Schneider M, Haas M, Glick R, Stevans J \& Landsittel D. A comparison of spinal manipulation methods and usual medical care for acute and Sub-acute low back pain: a randomized clinical trial. Spine. 2015;40:4:209.

57. Shah SG \& Kage V. Effect of seven sessions of posterior-to-anterior spinal mobilisation versus prone press-ups in nonspecific low back pain-randomized clinical trial. Journal of clinical and diagnostic research: Journal of Clinical and Diagnostic Research. 2016;10:3:YC10.

58. Sobral Monteiro-Junior R, Pereira de Souza C, Lattari E, Rocha BF, Mura G, Machado S \& Bezerra da Silva E. Wiiworkouts on chronic pain, physical capabilities and mood of older women: a randomized controlled double blind trial. CNS \& Neurological Disorders-Drug Targets. 2015; 14:9:1157-1164.

59. Starkweather AR, Coyne P, Lyon DE, Elswick RK, An K \& Sturgill J. Decreased Low Back Pain Intensity and Differential Gene Expression Following Calmare®: Results From a Double-Blinded Randomized Sham-Controlled Study. Research in Nursing \& Health. 2015; 38:1:29-38.

60. Steele J, Bruce-Low S, Smith D, Jessop D \& Osborne N. A randomized controlled trial of the effects of isolated lumbar extension exercise on lumbar kinematic pattern variability during gait in chronic low back pain. PM\&R. 2016; 8:2: 105-114.

61. Szulc P, Wendt M, Waszak M, Tomczak M, Cieślik K \& Trzaska T. Impact of McKenzie method therapy enriched by muscular energy techniques on subjective and objective parameters related to spine function in patients with chronic low back pain. Medical Science Monitor: International Medical Journal of Experimental and Clinical Research. 2015;21:2918.

( The Internet Journal of Allied Health Sciences and Practice, 2019 
62. Telles S, Bhardwaj AK, Gupta RK, Sharma SK, Monro R \& Balkrishna A. A randomized controlled trial to assess pain and magnetic resonance imaging-based (MRI-Based) structural spine changes in low back pain patients after yoga practice. Medical Science Monitor: International Medical Journal of Experimental and Clinical Research. 2016; 22: 3238.

63. Trapp W, Weinberger M, Erk S, Fuchs B, Mueller M, Gallhofer B, Hajak G, Kübler A \& Lautenbacher S. A brief intervention utilising visual feedback reduces pain and enhances tactile acuity in CLBP patients. Journal of Back and Musculoskeletal Rehabilitation. 2015;28:4: 651-660.

64. Van Dillen LR, Norton BJ, Sahrmann SA, Evanoff BA, Harris-Hayes M, Holtzman GW, Earley J, Chou I \& Strube MJ. Efficacy of classification-specific treatment and adherence on outcomes in people with chronic low back pain. A one-year follow-up, prospective, randomized, controlled clinical trial. Manual Therapy. 2016;24:52-64.

65. Vavrek D, Haas M, Neradilek MB \& Polissar N. Prediction of pain outcomes in a randomized controlled trial of doseresponse of spinal manipulation for the care of chronic low back pain. BMC Musculoskeletal Disorders. 2015; 16:1:205.

66. Wälti P, Kool J \& Luomajoki H. Short-term effect on pain and function of neurophysiological education and sensorimotor retraining compared to usual physiotherapy in patients with chronic or recurrent non-specific low back pain, a pilot randomized controlled trial. BMC Musculoskeletal Disorders. 2015; 16:1:83.

67. Waqqar S, Shakil-ur-Rehman S \& Ahmad S. McKenzie treatment versus mulligan sustained natural apophyseal glides for chronic mechanical low back pain. Pakistan Journal of Medical Sciences.2016; 32:2: 476.

68. Winter S. Effectiveness of targeted home-based hip exercises in individuals with non-specific chronic or recurrent low back pain with reduced hip mobility: A randomised trial. Journal of Back and Musculoskeletal Rehabilitation. 2015; 28:4: 811825.

69. Xia T, Long CR, Gudavalli MR, Wilder DG, Vining RD, Rowell RM, Reed WR, DeVocht JW, Goertz CM, Owens Jr EF \& Meeker WC. Similar effects of thrust and non-thrust spinal manipulation found in adults with subacute and chronic low back pain-A controlled trial with adaptive allocation. Spine. 2016; 41:12: E702.

70. Yeh CH, Kwai-Ping Suen L, Chien LC, Margolis L, Liang Z, Glick RM \& Morone NE. Day-to-day changes of auricular point acupressure to manage chronic low back pain: a 29-day randomized controlled study. Pain Medicine.2015; 16:10:18571869.

(c) The Internet Journal of Allied Health Sciences and Practice, 2019 